\title{
Cystatin C: A Marker of Renal Function
}

\author{
Md. Aminul Haque Khan ${ }^{1}$, Nasreen Chowdhury ${ }^{2}$, Md. Mozammel Hoque ${ }^{3}$ \\ Received: January 14, 2013 Accepted: December 15, 2013
}

\begin{abstract}
The most widely used investigation of renal function and GFR is the measurement of serum creatinine and creatinine clearance rate. This has been extremely popular in clinical medicine despite formidable difficulties associated with its quantification and interpretation. The main pathophysiological difficulties include variations in the rates of creatinine generation and its secretion by the renal tubules. Concentration of serum creatinine is now recognized as an unreliable measure of kidney function as it is affected by age, body weight, muscle mass, race and various medications. Several equations have been developed to improve the accuracy of serum creatinine level as a measure of GFR. The most widely used in adult populations are the Cockroft-Gault equation and the abbreviated Modification of Diet in Renal Disease (MDRD) equation. Even with these equations, measurement of GFR is difficult because the equations are less accurate with higher levels of kidney function and are affected by interlaboratory variation in measuring creatinine level. In the above perspective, cystatin $C$ concentration has become a promising marker for kidney function in both native and transplanted kidneys. Because of the possible potentiality of cystatin $C$ to be an emerging endogenous marker for quick and accurate assessment of renal function, we have decided to review elaborately on cystatin $C$ as a marker of renal function and to review the sensitivity and specificity of cystatin $C$ as an endogenous marker compared to serum creatinine. Results of our review study suggest that cystatin $C$ is a better marker of renal function compared to serum creatinine and other endogenous markers irrespective of age, sex and clinical condition.
\end{abstract}

Key words: Cystatin C; Renal function; GFR; Creatinine; Creatinine clearance

J Enam Med Col 2014; 4(2): 110-122

\section{Introduction}

The social and economic consequences of chronic renal failure are considerable. ${ }^{1}$ Acute renal failure (ARF) defined by a rapid decrease of glomerular filtration rate (GFR) is associated with high mortality. Early and accurate detection of decreasing GFR is critical to prevent the progression of acute renal failure and to potentially improve its outcome. ${ }^{2}$

The most widely used investigation of renal function and GFR is the measurement of serum creatinine and creatinine clearance rate. This has been extremely popular in clinical medicine despite formidable difficulties associated with its quantification and interpretation. $^{3}$ The main pathophysiological difficulties include variations in the rates of creatinine generation and its secretion by the renal tubules. ${ }^{4}$

Concentration of serum creatinine is now recognized as an unreliable measure of kidney function because it is affected by age, body weight, muscle mass, race and various medications. ${ }^{5,6}$ As muscle mass falls with age, less creatinine is produced each day. Serum creatinine can thus be a misleading guide in renal function in poorly nourished older people with low muscle mass. ${ }^{1}$ Creatinine clearance is not a perfect

1. Professor, Department of Biochemistry, Enam Medical College, Savar, Dhaka

2. Professor, Department of Biochemistry, Chattagram Maa-O-Shishu Hospital Medical College, Chittagong

3. Professor, Department of Biochemistry, Bangabandhu Sheikh Mujib Medical Univesity, Dhaka

Correspondence Md. Aminul Haque Khan, Email: aminhkhan@yahoo.com 
marker of GFR because a small amount of it is secreted by the tubules, so the amount of creatinine excreted slightly exceeds the amount filtered. ${ }^{7}$ The creatinine clearance can diminish quite significantly before the plasma creatinine increases above the reference intervals; thus, a normal plasma creatinine does not necessarily equate with normal renal function. Plasma creatinine level equates with renal function, only when the influence of muscle mass, exercise, and diet on creatinine level is duly considered. ${ }^{8}$

Several equations have been developed to improve the accuracy of serum creatinine level as a measure of GFR. The most widely used in adult populations are the Cockroft-Gault equation and the abbreviated Modification of Diet in Renal Disease (MDRD) equation. Even with these equations, measurement of GFR is difficult because the equations are less accurate with higher levels of kidney function and are affected by interlaboratory variation in measuring creatinine level. $^{9}$

A number of proteins with molecular weights of less than $30 \mathrm{kD}$ are predominantly cleared from the circulation by renal filtration and can be considered to be relatively freely filtered at the glomerular filtration barrier. These include $\beta_{2^{-}}$ microglobulin, retinol binding protein (RBP), $\alpha_{1}$-microglobulin and cystatin C. However, apart from cystatin $\mathrm{C}$, all the other proteins have been shown to have serum concentrations that are influenced by nonrenal factors such as inflammation ( $\beta_{2}$-microglobulin) and liver disease (RBP, $\alpha_{1}$-microglobulin). ${ }^{10-12}$

The relationship between the circulating concentrations of these proteins and renal function shows the same curvilinear form as seen in creatinine, but several groups have demonstrated that cystatin $\mathrm{C}$ measurement may offer a more sensitive and specific monitoring of changes of GFR than serum creatinine. ${ }^{12-14}$ With regard to renal function, its most important attributes are its small size and high isoelectric $\mathrm{pH}$ (9.2), which enable it to be more freely filtered than the abovementioned proteins at the glomerulus. ${ }^{11}$

Cystatin C is synthesized by all nucleated cells of body and the rate of its production is constant. ${ }^{11}$
Results from other studies have also indicated that serum concentrations of cystatin $\mathrm{C}$ are not influenced by muscle mass, diet or sex. ${ }^{13}$ It has no extrarenal routes of elimination, with clearance from the circulation only by glomerular filtration. ${ }^{11}$

While there is an acceptable correlation between serum or plasma cystatin $\mathrm{C}$ and creatinine, the correlation between the reciprocal of serum cystatin $\mathrm{C}$ and GFR as assessed by ${ }^{51} \mathrm{Cr}$-EDTA clearance $(\mathrm{r}=0.81)$ is superior to that with reciprocal of creatinine $(r=0.50) .{ }^{8}$

In the above perspective, cystatin $\mathrm{C}$ concentration has become a promising marker for kidney function in both native and transplanted kidneys. ${ }^{12}$ Therefore, cystatin C has been proposed as an endogenous marker for measuring glomerular filtration rate (GFR) and is regarded as being equivalent to or better than creatinine. Because of the possible potentiality of cystatin $\mathrm{C}$ to be an emerging endogenous marker for quick and accurate assessment of renal function we have decided to review elaborately on cystatin $\mathrm{C}$ as a marker of renal function and to review the sensitivity and specificity of cystatin $\mathrm{C}$ as an endogenous marker of renal function compared to serum creatinine.

\section{Renal function tests}

Various tests have been developed to assess the functions of kidneys. These include urinalysis, estimation of various nonprotein nitrogenous substances in blood and urine, clearance tests and other miscellaneous tests.

Glomerular filtration rate (GFR) is universally considered as a measure of the overall function of the kidney. ${ }^{1}$ The 'gold standard' for determining GFR is to measure the clearance of exogenous substances such as inulin, iohexol, ${ }^{51} \mathrm{Cr}$-EDTA, ${ }^{99} \mathrm{~m}$ Tc-labeled diethyleneamine pentaacetic acid (DTPA), or ${ }^{125}$ I-labeled iothalamate. ${ }^{15}$ Measurement of clearance of these substances is considered as 'gold standard' as these substances are exogenous, not produced in the body, distributed in the plasma at a uniform concentration, freely filtered (filtered as freely as water) at the glomerulus, have no extrarenal route for elimination and are neither reabsorbed nor secreted by the renal tubules and so, the rate at which these substances are excreted in the urine $\left(U_{c} \times V\right)$ is equal to their filtration rate by the kidneys $\left(\mathrm{GFR} \times \mathrm{P}_{\mathrm{c}}\right)$. However, measurement of GFR based on clearance of these substances is time- 
consuming, labor-intensive, expensive and requires intravenous administration that make it incompatible with routine monitoring. So, the measurement of clearance of endogenous substances is a common practice. ${ }^{15}$ Moreover, several equations have been developed for measurement of glomerular filtration rate. These are Cockroft-Gault equation, MDRD equation for adult populations. Such formulae for pediatric populations are Schwartz and Counahan-Barratt equations. But it is unwise to expect any of these equations to perform well in unusual circumstances, such as extreme of body mass, poorer levels of kidney function etc. ${ }^{1}$

Properties of an ideal endogenous blood substance to estimate GFR include a constant rate of release in blood, free filtration by the glomerulus, no reabsorption or secretion by the renal tubules and exclusive elimination through the kidneys.

Blood urea nitrogen was the first endogenous substance measured in serum or plasma to assess renal function. It is a major by-product of protein metabolism and more than $90 \%$ of urea is cleared by kidneys. ${ }^{15}$ Urea is freely filtered by glomerulus and not secreted by the renal tubules. However, a large portion (around 50\%) is passively reabsorbed from the tubules. ${ }^{7}$ Thus its concentration underestimates GFR because some of the urea that is filtered returns to the blood stream. Furthermore, its concentration in the blood varies with diet, hepatic function and numerous disease states. ${ }^{8}$ Later on serum or plasma creatinine ( $\mathrm{SCr}$ ) has become the most commonly used serum marker of renal function. ${ }^{15}$ Creatinine is a metabolic product of creatine and phosphocreatine in muscle tissue. Its rate of appearance in the circulation is related to muscle mass and therefore, intraindividual concentrations are relatively constant. However, serum creatinine concentrations are affected by age, gender, weight, race and various medications. ${ }^{15}$

Creatinine circulates in the blood unbound to any plasma proteins and is freely filtered through the glomerulus. It is not reabsorbed by the renal tubules, but is secreted in small amounts, which are subject to intraindividual and interindividual variation. ${ }^{16}$ As plasma concentrations increase, tubular secretion of creatinine increases, leading to an overestimation of GFR in patients with moderate to severe decreases in GFR $(<50 \mathrm{~mL} / \mathrm{min}) .{ }^{16}$ Serum creatinine is also insensitive for detecting small decreases in GFR because of the nonlinear relationship between plasma concentration and GFR. Finally, the most common method (picric acid) for analyzing serum creatinine is subject to analytic interferences from substances such as glucose, uric acid, ketones, plasma proteins and cephalosporins. $^{3}$ Because of multifarious limitations of the commonly used endogenous markers, the search for an ideal endogenous marker of GFR continues.

\section{Cystatin C}

Cystatin $\mathrm{C}$ is a $13 \mathrm{kDa}$ low molecular weight protein composed of 120/122-amino acids. It is a member of the family cysteine proteinase inhibitors. Cystatin C is a product of 'house keeping' gene and is synthesized by all nucleated cells of body and the rate of its production is constant. ${ }^{11}$

Cystatin $\mathrm{C}$ is cleared from the circulation by only renal filtration and is freely filtered at the glomerular filtration barrier. Its serum concentration is not influenced by nonrenal factors. ${ }^{10-12}$ Its small size and high $\mathrm{pI}$ enable it to be freely filtered at the glomerulus. ${ }^{11}$

The use of serum cystatin C to estimate GFR is based on the same logic similar to that for blood urea nitrogen and creatinine. But because it is neither reabsorbed nor secreted by renal tubules, it is suggested to be closer to the ideal endogenous marker. ${ }^{15}$

Cystatin $\mathrm{C}$ plays role in many biological processes, such as degradation of cellular proteins, regulation of enzymes and many pathologic processes. It is present in all body fluids and is important in arterial wall remodeling and atherogenesis. ${ }^{11,17}$ It also predicts hyperchromocysteinemia, Alzheimer's disease, leukoencephalopathy with progressive dementia, impairment of the blood-brain barrier and degenerative diseases of the retina. ${ }^{17}$

\section{Measurement of cystatin $C$}

Cystatin $\mathrm{C}$ can be measured by particle-enhanced nephelometric immunoassay (PENIA). The assay covers the range from 0.23 to $7.25 \mathrm{mg} / \mathrm{L}$, up to seven times the upper limit of normal. There is absolute linearity across the assay range. It can 
also be measured by particle-enhanced turbidimetric immunoassay (PETIA). Both the assay methods agree well with each other. Hemoglobin, bilirubin, triglycerides, rheumatoid factor, myeloma paraproteins do not interfere with the assay. ${ }^{14}$

There may be statistically significant but small difference between the serum and plasma cystatin $\mathrm{C}$. There is no significant difference in cystatin $\mathrm{C}$ levels of fresh specimens and those measured 2 days after storage at room temperature, 1 week after storage at $4^{0} \mathrm{C}$, or 1 month at $-20^{0} \mathrm{C}$. Cystatin $\mathrm{C}$ is thus considered stable at all temperatures over these time periods. ${ }^{14}$

\section{Review of some studies examining cystatin C as a marker of renal function}

Since physiological processes other than GFR determine the serum creatinine level ${ }^{18}$, cystatin $\mathrm{C}$ has been proposed as an endogenous marker for measuring glomerular filtration rate (GFR) and is regarded as being equivalent to or better than creatinine. ${ }^{19}$ Here we have reviewed a number of studies on cystatin $\mathrm{C}$ as a renal function marker.

In a study involving 144 patients, aged more than 60 years (mean age 70.4 years), who had undergone ${ }^{51} \mathrm{Cr}$-EDTA clearance, the investigators found a significant correlation between ${ }^{51} \mathrm{Cr}$-EDTA clearance and serum creatinine, serum cystatin $\mathrm{C}$, the reciprocal of serum creatinine, the reciprocal of serum cystatin $\mathrm{C}$ as well as with creatinine clearance. In each patient serum creatinine and serum cystatin $\mathrm{C}$ were determined. The reciprocal of serum creatinine, the reciprocal of serum cystatin $\mathrm{C}$ and creatinine clearance were calculated. The creatinine clearance was calculated from Cockroft and Gault formula. Serum cystatin $C$ was measured with the particle enhanced immunonephelometric method. ${ }^{20}$ In comparison of the correlation coefficients they found that the correlation between ${ }^{51} \mathrm{Cr}$-EDTA clearance and serum cystatin $\mathrm{C}$ was significantly better than that with serum creatinine. The correlation between ${ }^{51} \mathrm{Cr}$-EDTA clearance and the reciprocal of serum cystatin $\mathrm{C}$ was superior to that with reciprocal of serum creatinine and calculated creatinine clearance. There are other studies consistent with this study. ${ }^{21,22}$

In one study involving 50 critically ill patients, the researchers showed that serum cystatin $\mathrm{C}$ correlated better with GFR than did creatinine. Serum creatinine, serum cystatin $\mathrm{C}$ and 24-hours creatinine clearance $(\mathrm{CCr})$ were determined in these critically ill patients (age 21-86 years). They did not have chronic renal failure, but were at risk of developing renal dysfunction. Serum cystatin $\mathrm{C}$ was measured using particle enhanced immunonephelometry. 24-hours body surface adjusted $\mathrm{CCr}$ was used as a control, considering it as 'gold standard' for determining GFR. ${ }^{23}$ The results of the study showed that serum cystatin $\mathrm{C}$ correlated better with GFR than did creatinine (1/Cyastatin $\mathrm{C}$ versus $\mathrm{CCr}$ : $\mathrm{r}=0.832, \mathrm{p}<0.001 ; 1 /$ Creatinine versus $\mathrm{CCr}: \mathrm{r}=0.426$, $\mathrm{p}=0.002)$. The investigators concluded that cystatin $\mathrm{C}$ is an accurate marker of subtle changes in GFR, and it might be superior to creatinine when assessing this parameter in clinical practice, specially in critically ill patients. $^{23}$ But some investigators disagree with this study regarding the value of cystatin $\mathrm{C}$ as a measure of glomerular filtration rate in critically ill patients. ${ }^{24}$ They also disagree that cystatin $\mathrm{C}$ can be used as a marker of GFR in intensive care patients. This inconsistency among studies on critically ill patients may be due to small size or less standard method of estimating cystatin C.

In one study involving 151 patients (91 had normal renal functions and 60 sufferred from renal insufficiency of different severity) from a nephrological out-patient clinic in Czechoslovakia, the investigators found close correlation $(r=-0.787)$ between cystatin $\mathrm{C}$ and glomerular filtration assessed by creatinine clearance. ${ }^{21}$ The authors evaluated separately a group of 36 patients with glomerulonephritis, 34 diabetic patients with diabetic nephropathy, 38 patients with tubulointerstitialnephritis and 43 subjects with other kidney diseases. There was not significant difference in respect of correlation between cystatin $\mathrm{C}$ and glomerular filtration assessed by creatinine clearance. The authors of the study confirmed that a good correlation of cystatin $\mathrm{C}$ with creatinine filtration was not influenced by the type of basic nephrological disease. $^{21}$

In another study diagnostic significance of serum cystatin C levels in clinical practice was evaluated. ${ }^{22}$ Serum ${ }^{99 \mathrm{~m}}$ Tc-DTPA clearance was compared with serum cystatin $C$, creatinine, $\beta_{2}$-microglobulin levels and creatinine clearance in a group of 52 patients aged $42.61 \pm 7.55$ years with impaired 
kidney function with glomerular filtration rates of $10-60 \mathrm{~mL} / \mathrm{min} / 1.73 \mathrm{~m}^{2}$. It was shown that reference clearance correlated better with cystatin $\mathrm{C}$ $(\mathrm{r}=0.828)$ than with creatinine $(\mathrm{r}=0.682)$.

In a study it was shown that cystatin $\mathrm{C}$ shows a high correlation with GFR and because of low biological variation cystatin $\mathrm{C}$ gives also a good assessment of GFR changes during follow-up. ${ }^{25}$ In this study plasma specimens were obtained from 93 (with equal number of male and females) consecutive patients seen for GFR determination. GFR was determined with $\left[{ }^{125} \mathrm{I}\right]$ iothalamate. Plasma creatinine was determined enzymatically and the creatinine clearance was calculated according to Cockroft \& Gault equation. Cystatin $\mathrm{C}$ was measured with a particle-enhanced immunonephelometric method.

In the study GFR correlated with 1/cystatin C $(\mathrm{r}=0.873)$ as well as with Cockroft \& Gault equation $(r=0.876)$. Cystatin $C$ levels started to become abnormal at a GFR level of $80-90 \mathrm{~mL} /$ minute $/ 1.73$ $\mathrm{m}^{2}$ range whereas the GFR did reach the value $60-70$ $\mathrm{mL} /$ minute $/ 1.73 \mathrm{~m}^{2}$ range before creatinine exceeded the upper reference limit. In conclusion, the authors supported the value of cystatin $\mathrm{C}$ as the endogenous parameter for estimation of GFR. From this study it can also be inferred that serum cystatin $\mathrm{C}$ is an early marker of renal dysfunction. Another study by Herget-Rosenthal et $\mathrm{al}^{2}$ also supports this inference. ${ }^{25}$

In the study, 30 patients with type 2 diabetes mellitus of whom 18 were males and 12 were females were also included. The day-to day variation (biological + analytical) for cystatin $\mathrm{C}$ was small $(3.1 \%)$ in diabetic patients. In the follow-up study in diabetic patients, cystatin $\mathrm{C}$ was the parameter which had the best correlation $(r=0.66)$ with changes in GFR. The investigators concluded that in type 2 diabetic patients, cystatin $\mathrm{C}$ was also the best parameter for follow-up of GFR changes. ${ }^{25}$

A prospective study was done to evaluate whether serum cystatin $\mathrm{C}$ detected the onset of acute renal failure earlier than serum creatinine. ${ }^{2}$ In this study, 85 patients at high risk to develop acute renal failure (ARF), serum creatinine and serum cystatin $\mathrm{C}$ were determined daily. Forty-four patients developed ARF and forty-one served as controls. The increase of serum cystatin $\mathrm{C}$ significantly preceded that of creatinine. Serum cystatin C increased already $\geqslant 50 \%$ nearly 2 (two) days earlier compared to creatinine. The authors concluded that serum cystatin $\mathrm{C}$ is a useful marker to identify patients who will develop acute renal failure.

Additionally, low $\mathrm{T}_{3}$ or $\mathrm{T}_{3} / \mathrm{T}_{4}$ syndrome, glucocorticoid deficiency and excess did not affect cystatin $\mathrm{C}$ levels, adding to its usefulness in critically ill patients.

In a study on healthy subjects done by Keevil et al it was shown that serum creatinine concentrations were higher in men than women $(95.9 \pm 13.2 \mu \mathrm{mol} / \mathrm{L}$ vs $71.5 \pm 5.6 \mu \mathrm{mol} / \mathrm{L}$ ), but cystatin $\mathrm{C}$ concentrations showed no sex difference $(0.658 \pm 0.05 \mathrm{mg} / \mathrm{L}$ vs $0.630 \pm 0.08 \mathrm{mg} / \mathrm{L}){ }^{26}$

Another study was done on 460 adult subjects with the objective to compare cystatin $\mathrm{C}$ with serum creatinine for estimating GFR among different clinical presentations. Cystatin $\mathrm{C}$ and serum creatinine levels were obtained from adult patients during the evaluation that included a GFR measurement by iothalamate clearance. The association between serum cystatin $\mathrm{C}$ and GFR differed across clinical presentations. At the same cystatin C level, GFR was 19\% higher in transplant recipients than in patients with native kidney disease. The correlation between cystatin C and GFR among patients with native kidney disease $(n=204)$ was slightly higher $(r=0.853)$ than that between serum creatinine and GFR $(\mathrm{r}=0.827)$. The authors concluded that cystatin $\mathrm{C}$ should not be interpreted as purely a marker of GFR. Other factors, possibly inflammation or immunosuppression therapy, affect cystatin $\mathrm{C}$ levels. While recognizing this limitation, cystatin C may improve GFR estimates in chronic kidney disease patients. ${ }^{27}$

To compensate the drawbacks of serum creatinine as a GFR marker, several prediction equations have been developed. Of these Modification of Diet in Renal Disease (MDRD), Schwartz, and CounahamBaratt equations are the ones most widely accepted for estimation of GFR in $\mathrm{mL} /$ minute $/ 1.73 \mathrm{~m}^{2}$ body surface area. Grubb et al conducted a study on 536 patients to analyze whether these GFR prediction equations for adults and children could be replaced by simple prediction equations based on plasma concentrations of cystatin C. ${ }^{28}$ In this study on 536 
patients (4 months to 93 years), GFR was determined by an invasive gold standard procedure. A cystatin $\mathrm{C}$-based prediction equation using concentration in $\mathrm{mg} / \mathrm{L}$ assessd GFR equally well or better than the MDRD, Schwartz, and Counahan-Barratt equations. The cystatin C-based equation is given below.

GFR $\left(\mathrm{mL} / \mathrm{m} / 1.73 \mathrm{~m}^{2}\right)=84.69 \times$ cystatin $\mathrm{C}(\mathrm{mg} / \mathrm{L})^{-1.680}$ $\times 1.384$ (if $<14$ years)

The authors concluded that a GFR prediction equation based solely on cystatin $\mathrm{C}$ (in $\mathrm{mg} / \mathrm{L}$ ) and a prepubertal factor might replace the simplified MDRD prediction equation for adults and the Schwartz and Counahan-Barratt prediction equations for children. ${ }^{28}$

Impaired renal function and end-stage renal disease (ESRD) affect up to one-third of patients with type 1 diabetes. Strategies for early detection and for preventive interventions are of critical importance. So, paramount importance is placed on the finding of microalbuminuria as an early marker of a committed process of progressive kidney disease in diabetics. But microalbuminuria is a marker of dynamic rather than fixed, kidney injury. A simple assay for cystatin $\mathrm{C}$ can calculate the slope of glomerular filtration rate change over time, suggesting it as a more proximal marker than microalbuminuria of a person's trajectory toward impaired renal function and ESRD. ${ }^{29}$

An epidemiological study was done to assess correlation among cystatin $\mathrm{C}$, serum creatinine and albuminuria in type 2 diabetic patients for assessment of early renal failure. The investigators concluded that measurement of serum cystatin $\mathrm{C}$ can be considered as a screening test for assessment of early renal failure in type 2 diabetic patients. ${ }^{30}$ On the contrary, Oddoze et al have shown that cystatin $\mathrm{C}$ is not more sensitive than creatinine for detecting early renal impairment in patients with diabetes. They evaluated serum cystatin $\mathrm{C}$ as a potential new marker of glomerular filtration rate in 49 patients who had steady-state diabetes with early renal impairment. GFR was measured by ${ }^{51} \mathrm{Cr}$-EDTA. Serum cystatin $C$, serum creatinine and $\beta 2-$ microglobulin levels were determined. Correlation coefficients with GFR were -0.77 for serum creatinine level, -0.71 for serum $\beta 2$-microglobulin and -0.65 for serum cystatin $\mathrm{C}$. The investigators concluded that serum cystatin $\mathrm{C}$ is not better than serum creatinine or serum beta-2 microglobulin for estimating GFR in patients with steady-state diabetes. ${ }^{31}$ The difference with the previous studies might be due to small sample size of this study.

A 4-year follow-up study was done to assess how well serum cystatin $C$ meets the need of a renal function marker for detecting trends in early renal function over time in diabetic patients when GFR is normal or elevated. The study was conducted on 30 subjects with type 2 diabetes. GFR was measured by iothalamate clearance. 4 years follow-up was done with yearly measurements of iothalamate clearance based GFR and serum cystatin C. With the use of linear regression, each individual's trend in renal function over time, expressed as annual percentage change in iothalamate clearance, was determined. Serum cystatin $\mathrm{C}$ in $\mathrm{mg} / \mathrm{dL}$ was transformed to its reciprocal. Linear regression was used to determine each individual's trend over time. The trends in reciprocal of cystatin $\mathrm{C}$ and iothalamate clearance strongly correlated $(r=0.77)$. Results were discordant for only three participants. In contrast, the trends for three commonly used creatinine-based estimates of GFR compared poorly with trends in iothalamate clearance $(r<0.35) .29$ Finally, the investigators concluded that serial measures of serum cystatin $\mathrm{C}$ accurately detect trends in renal function in patients with normal or elevated GFR and provide means for studying early renal function decline in diabetes. ${ }^{29}$

Another study was done by Uslu et al to determine whether the serum cystatin $\mathrm{C}$ and activities of some tubular enzymes could be used as screening markers for early renal dysfunction in diabetic patients. The study was done on 56 diabetic patients and 20 healthy subjects as controls. ${ }^{32}$ Serum cystatin C levels and urinary activities of N-accetyl-b-Dglucosaminidase (NAG), alkaline phosphatase (ALP) and lactate dehyrogenase (LDH) were measured. The results were compared with serum creatinine $(\mathrm{Cr})$ and creatinine clearance $(\mathrm{CCr})$ estimated with Cockroft-Gault formula and 24-hours urine microalbuminuria (MAU). Serum cystatin C levels were found elevated as compared to controls both in normoalbuminurics and microalbuminurics. Serum cystatin $\mathrm{C}$ levels started to increase above the normal range when $\mathrm{CCr}$ declined while serum creatinine was in the normal range. The investigators concluded that 
serum cystatin $\mathrm{C}$ had higher sensitivity than serum creatinine and met the criteria for detecting glomerular dysfunction as screening tests for early diagnosis of diabetic nephropathy and so could be useful as screening markers to follow-up glomerular dysfunction in diabetic patients. ${ }^{31}$ This study is also consistent with the previous one. ${ }^{29}$

A study was done to assess the use of serum cystatin $\mathrm{C}$ as a marker of renal function in kidney transplant patients. The study was done among 78 patients undergoing kidney transplantation. Serum cystatin C was compared with serum creatinine and with creatinine clearance either in a 24-hour urine or calculated using the Cockroft-Gault formula. The parameters were determined at 2, 5, 7, 15 and 30 days and 6, 12 and 18 months after transplantation. During the first 30 days following transplantation, there was a progressive decline in serum creatinine levels. Serum cystatin C increased up to the fifth day, coinciding with the highest doses of steroids, and then decreased. At 6,12 and 18 months, there was a correlation between serum cystatin $\mathrm{C}$ and serum creatinine, creatinine clearance in 24-hours urine or GFR calculated with the Cockroft-Gault formula $(r=0.859, r=-0.713$ and $r=-0.684)$. The authors concluded that serum cystatin $\mathrm{C}$ is an endogenous marker of GFR in kidney transplant patients with limitations relating to its being affected by the high doses of steroids in the first few days following transplantation. ${ }^{33}$

A study was done to evaluate the accuracy of cystatin $\mathrm{C}$ as a marker of glomerular filtration in 62 children before and after liver transplantation. They had their ${ }^{51} \mathrm{Cr}$-EDTA measured GFR on 40 occasions prior to transplantation and on 47 occasions after liver transplantation. The reciprocal of cystatin $\mathrm{C}$ correlated better with ${ }^{51} \mathrm{Cr}$-EDTA GFR $(r=0.78)$ than the reciprocal of creatinine $(r=0.40)$. A level of $1.06 \mathrm{mg} / \mathrm{L}$ was found to have a sensitivity of $91 \%$ and a specificity of $81 \%$. The investigators concluded that the use of serum cystatin $\mathrm{C}$ measurement could be recommended as screening of renal dysfunction in children with liver disease and after liver transplantation. ${ }^{34}$

Another study was done to assess cystatin $\mathrm{C}$ as a marker and to compare it with serum creatinine in 44 cirrhotic patients. The investigators analyzed correlation, bias, precision and accuracy of two cystatin C-based formula (Larsson and Hoek) for GFR estimation in comparison with two creatininebased equations (Cockroft \& Gault and MDRD). The GFR was measured by inulin clearance. Creatinine as well as cystatin C-based equations overestimated the true GFR by 105-154\%. However, cystatin C-based equations showed significantly lower bias and higher precision than the creatinine-based formulae. The investigators concluded that the study suggested a significant improvement of GFR estimation in liver cirrhotics by means of cystatin $\mathrm{C}$ level. They also concluded that cystatin C-based estimates in cirrhotics remained a crude approximation of true GFR and cannot replace gold standard methods. ${ }^{35}$

Akbari et al conducted a prospective study on 150 subjects to assess the validity of cystatin $\mathrm{C}$ as a clinical marker of glomerular filtration rate in pregnant women. They concluded that cystatin $\mathrm{C}$ was a poor marker of GFR during pregnancy and the investigators urged caution against the use of cystatin $\mathrm{C}$ as a marker of GFR in pregnancy. ${ }^{36} \mathrm{On}$ the other hand one group studied third trimester subjects and claimed cystatin $\mathrm{C}$ to be a very reliable marker of GFR and also claimed it to be superior to creatinine. ${ }^{37}$ In other studies it was shown that measurement of serum cystatin $\mathrm{C}$ was a useful clinical tool as a marker of GFR in pregnancy induced hypertension. ${ }^{38,39}$ The inconsistency among these studies is expected to be solved in favor of cystatin $\mathrm{C}$ by a large scale study on pregnant women.

Another study was done to evaluate the diagnostic utility of cystatin $\mathrm{C}$ as a marker of glomerular filtration rate in hypertensive disorders of pregnancy. One hundred ninety eight women with hypertension were included in the study. The 24-hour urine creatinine clearance was used as the 'gold standard' for evaluation of glomerular filtration rate due to concerns of radiation exposure to pregnant women. Serum cystatin $\mathrm{C}$ showed a significant correlation with creatinine clearance at the 0.01 level with an $\mathrm{r}-$ value of -0.311 . The authors concluded that serum cystatin $\mathrm{C}$ reflected glomerular filtration rate reliably in hypertensive pregnant women and could avoid the inaccuracy associated with the 24-hours urine collection. $^{40}$

Filler et al conducted a study on 262 children aged 1 to 18 years with various renal pathologies to 
compare the feasibility of the Cockroft-Gault formula against the standard pediatric Schwartz formula and cystatin C-based formula. The subjects underwent a 99-technetium diethylenetriaminepentaacetate ( ${ }^{99}$ Tc-DTPA) glomerular filtration (GFR) rate scan. Cockroft-Gault formula showed the worst agreement with GFR and the cystatin C-based approach showed the best agreement. The investigators concluded the cystatin C-based approach should be used for estimation of GFR in pediatric populations. ${ }^{41}$

Another study was done to compare the diagnostic accuracy of cystatin $\mathrm{C}$ with serum creatinine and the Schwartz formula for estimating GFR in pediatric patients with urinary tract malformations. ${ }^{42}$ The investigators prospectively compared 72 patients (20 days to 36 months old, 58 males and 14 females) with urinary tract malformations with a group of 72 healthy controls (10 days to 48 months old, 53 males and 19 females). All subjects underwent nuclear medicine clearance investigations with ${ }^{99 m} \mathrm{Tc}$ DTPA. In this study, serum concentration of cystatin $\mathrm{C}$ showed a higher correlation with reference GFR $(r=0.62)$ than serum creatinine $(r=0.30)$ and Schwartz formula $(\mathrm{r}=0.51)$. The investigators concluded that serum cystatin $\mathrm{C}$ as a marker of renal function was superior to serum creatinine in children younger than 3 (three) years. ${ }^{42}$

Podracka et al conducted a study in the face of controversy about the feasibility of cystatin $\mathrm{C}$ as a marker of glomerular filtration rate in pediatric solid organ (kidney, liver and liver + kidney) transplant recipients. ${ }^{43}$ The mean age of the recipients was 7.0 \pm 5.6 years. They studied intrapatient variability of cystatin $\mathrm{C}$ in comparison with serum creatinine. In this study, a total of 178 simultaneous $\mathrm{SCr}$ and cystatin $\mathrm{C}$ measurements were analyzed. In addition, GFR was calculated using the Schwartz and cystatin $\mathrm{C}$-based formulae. Intraindividual coefficients of variation $(\mathrm{CV})$ was calculated as a ratio of standard deviation over mean. Statistical analysis suggested that cystatin $\mathrm{C}$ and cystatin C-based calculated GFR was equivalent but not better than serum creatinine and Schwartz formula. Finally they concluded that measurement of cystatin $\mathrm{C}$ could be used for followup of renal function of pediatric solid organ posttransplants. $^{43}$ All these studies on pediatric populations are consistent with each other and recommend cystatin $\mathrm{C}$ as a useful renal function marker in pediatric populations in different settings.

Ozer et al conducted a study on primary hypertensive patients to assess whether cystatin $\mathrm{C}$ can be a better marker for the early detection of renal damage. The study was done on 51 primary hypertensive patients and 29 age and sex matched healthy controls. GFR calculated by MDRD was used as reference. In all subjects serum cystatin $C$, serum creatinine, $\beta_{2}-$ microglobulin and some other parameters were measured. Mean levels of the serum parameters were found to be significantly higher in the patient group compared to control group. Cystatin $\mathrm{C}$ was found to be superior to other markers. The investigators concluded that compared to other traditional markers, measurement of serum cystatin $\mathrm{C}$ might be a better parameter to estimate GFR, especially to detect mild reductions in GFR in primary hypertensive patients. ${ }^{44}$

Artunc et al compared serum creatinine and cystatin $\mathrm{C}$ levels in 127 patients undergoing cardiac catheterization. The clearance of the iodinated contrast dye iopromide served as reference method for GFR. Serum cystatin C was determined by particle-enhanced immunonephelometric method. Cystatin $\mathrm{C}$ showed higher correlation $(\mathrm{r}=0.805)$ to the iopromide clearance compared to creatinine $(r=0.652)$ and to the estimated GFR according to the Cockroft-Gault formula $(\mathrm{r}=0.690)$. At a cut-off level of $>1.3 \mathrm{mg} / \mathrm{L}$, cystatin $\mathrm{C}$ exhibited an $88 \%$ sensitivity and a $96 \%$ specificity for detecting renal dysfunction which was defined as an iopromide clearance $<80 \mathrm{~mL} /$ minute $/ 1.73 \mathrm{~m}^{2}$ body surface; best values for creatinine were $63 \%$ for sensitivity and $80 \%$ for specificity at a cut-off value of $>1.2$ $\mathrm{mg} / \mathrm{dL}$. The investigators concluded that cystatin $\mathrm{C}$ detected reduced GFR more reliably and at an earlier stage in patients undergoing cardiac catheterization allowing a better identification of patients with renal dysfunction. ${ }^{45}$

A study was done to assess the value of cystatin $\mathrm{C}$ in quantifying clinical and subclinical renal injury following on-pump and off-pump cardiac surgery. For the purpose, sixty consecutive patients were recruited - 30 patients undergoing on-pump CABG (coronary artery bypass grafting) and 30 patients undergoing off-pump CABG. Blood specimens were collected preoperatively and on days 1,2 and 4 
postoperatively to measure serum creatinine and serum cystatin $\mathrm{C}$. Cystatin $\mathrm{C}$ and creatinine correlated strongly with each other. The investigators concluded that cystatin $\mathrm{C}$ proved to be a simple and sensitive measure of overall renal function. ${ }^{46}$

In patients with thyroid dysfunction, cystatin $\mathrm{C}$ is not a suitable measure of GFR as cystatin C levels are low in hypothyroidism and elevated in hyperthyroidism. ${ }^{24,47}$ However, many of the hyperthyroid and hypothyroid patients have normal serum cystatin $\mathrm{C}$ values. ${ }^{47}$ Because of inconsistency of serum cystatin $\mathrm{C}$ values in patients with thyroid dysfunction, its value to assess renal function in thyroid disorders is limited. Further studies are required to come to a final conclusion.

A study was conducted to investigate changes in serum cystatin $\mathrm{C}$ concentration during membrane hemodialysis (HD-I, HD-II) and relationship between serum cystatin $\mathrm{C}$ and creatinine concentrations. There was close correlation between serum cystatin $\mathrm{C}$ and creatinine before hemodialysis. Serum cystatin $\mathrm{C}$ increased after hemodialysis due to its nondialysability through the membrane. Thus, serum cystatin $\mathrm{C}$ reflects the residual renal function even after hemodialysis. ${ }^{48}$

There is some evidence that cystatin C concentrations are not affected by the presence of malignancies or inflammation. ${ }^{49}$ On the other hand Kos et al have observed in their study a significant correlation between increased serum cystatin $\mathrm{C}$ and malignant progression in melanoma and colorectal cancer. ${ }^{50}$

Demirtas et al conducted a study on 19 leukemic patients to evaluate the influence of malignancy and the impact of nephrotoxic drugs used in bone marrow transplantation (BMT) on the circulating levels of cystatin $\mathrm{C}$ in leukemia. Cystatin $\mathrm{C}$, urea, creatinine, and creatinine clearance $(\mathrm{CrCl})$ were measured 24 hours before BMT, 1 week after BMT, 2 weeks after BMT and 3 weeks after BMT. The control group consisted of age and sex matched 20 healthy adults. At the pretransplantation period and one week after BMT, values of cystatin C were significantly higher than the values in the control group, whereas the levels of urea, creatinine and creatinine clearance were in accordance with the levels of the controls. Two and three weeks after
BMT, cystatin $\mathrm{C}$ values maintained the significant increase, whereas the values of urea, creatinine and creatinine clearance still corresponded with those of the controls. Results of their study suggested that cystatin $\mathrm{C}$ is not a reliable marker of GFR in patients during leukemia or for monitoring nephrotoxic drugs used in BMT. However, the investigators could not reach definitive conclusion due to no gold standard for comparing the diagnostic accuracy of cystatin C. ${ }^{51}$ As the investigators could not reach a definitive conclusion to evaluate the influence of malignancy and impact of nephrotoxic drugs used in BMT on the circulating levels of cystatin $\mathrm{C}$ in leukemic patients, further studies are needed in this regard.

The individual dosing of cytotoxic drugs that are mainly eliminated unchanged in the urine is made possible by assessing renal function. Carboplatin and topotecan are the two well-known drugs whose elimination is mostly dependent on the GFR. ${ }^{52} \mathrm{~A}$ prospective clinical trial including 45 patients was conducted to assess the value of serum cystatin $\mathrm{C}$ as a predictor of carboplatin clearance. The authors concluded that cystatin $\mathrm{C}$ is a marker of drug elimination that is at least as good as serum creatinine for predicting carboplatin clearance. ${ }^{51}$ Another study was done on 59 patients who underwent drug monitoring for individual dosing of topotecan. The authors concluded that cystatin $\mathrm{C}$ was a marker of drug elimination which was superior to serum creatinine for topotecan. ${ }^{53}$

Many investigators are already using serum cystatin $\mathrm{C}$ as a marker of renal function for their scientific studies. Fried et al conducted a study on 4637 participants to explore the association of kidney function with total noncardiovascular mortality. Kidney disease was assessed using cystatin $\mathrm{C}$ and estimated GFR. ${ }^{54}$ Ricci \& Ronco summarized all original research in the field of critical care nephrology published in 2004 or accepted for publication in Critical Care and other journals. Articles were grouped into four categories. In the third category, articles using cystatin $\mathrm{C}$ as an early marker of ARF were examined. 55

Shlipak et al performed a meta-analysis of 16 studies (with 93710 participants) for whom standardized measurements of serum creatinine and cystatin $\mathrm{C}$ were available. They concluded that the use of cystatin $\mathrm{C}$ alone or in combination with creatinine 
strengthens the association between the GFR and the risks of death and end stage renal disease across diverse populations. ${ }^{56}$

Inker et $\mathrm{al}^{57}$ have shown that combined creatininecystatin $\mathrm{C}$ equation performed better than equation based on either serum creatinine or serum cystatin $\mathrm{C}$ levels.

Teo et al $^{58}$ performed a study on GFR estimation equations using serum cystatin $\mathrm{C}$ combined with standardized creatinine in a multi-ethnic Asian population with CKD. They concluded that the use of cystatin $\mathrm{C}$ and creatinine combination equation for estimating GFR in a multi-ethnic Asian population with CKD does not require ethnicity coefficients as the derived coefficients are very close to each other.

\section{Discussion}

Attention is being paid globally to chronic kidney diseases because of rapid increase in its prevalence and the enormous cost of treatment and increasing risk of cardiovascular diseases. Recent data indicates that overt disease is the tip of an iceberg of covert diseases. Data from the United States suggest that for every patient with end-stage renal disease (ESRD), there are more than 200 with overt chronic kidney disease and almost 500 with covert diseases. These factors have rendered chronic kidney diseases an important focus in the health care planning. ${ }^{59}$ It is estimated that by the year 2030 , more than $70 \%$ of patients with ESRD will be residents of developing countries. $^{59}$

Acute renal failure is associated with high mortality. Early and accurate detection of decreasing GFR is critical to prevent the progression of acute renal failure and to potentially improve its outcome. Detection of biochemical abnormality which is the first manifestation of chronic renal failure will have impact on the total management of the patient and prevention of end-stage renal disease.

For assessing renal function, measurement of clearance of endogenous substances is a common practice. ${ }^{15}$ But, because of multifarious limitations of the commonly used endogenous markers, the search for an ideal endogenous marker of GFR continues.

So far, serum or plasma creatinine ( $\mathrm{SCr}$ ) has been being used as the commonest and most reliable serum marker of renal function in spite of its manifold limitations. To overcome these limitations, serum cystatin C-based approach is being claimed as better than serum creatinine for assessment of renal function. Many studies in this regard has been done abroad. We reviewed a few of these studies on different types of populations.

Studies we reviewed have shown significant correlation between cystatin $\mathrm{C}$ level and reference clearance and this correlation was also found to be superior to correlation between serum creatinine and reference GFR. Study on critically ill patients has also shown better correlation between cystatin $\mathrm{C}$ and GFR than it is between serum creatinine and GFR.

Serum cystatin $\mathrm{C}$ has been found as an early marker of renal dysfunction in comparison to serum creatinine and microalbuminuria. It has also been found to be the best parameter for follow-up changes in GFR in type 2 diabetic patients. Cystatin $C$ has also been found as a more proximal marker of GFR than microalbuminuria in type 1 diabetics.

Among patients with native kidney diseases, correlation between cystatin $\mathrm{C}$ and reference GFR was found a bit higher than it is between serum creatinine and reference GFR.

Cystatin $\mathrm{C}$ can be used as an endogenous marker of GFR in kidney transplant patients. GFR can also be estimated in liver cirrhotics by means of cystatin $\mathrm{C}$. However, the value of cystatin $\mathrm{C}$ to assess renal function in thyroid disorders is limited and requires more studies.

Cystatin C-based prediction equations for GFR may well replace the Cockroft-Gault and MDRD prediction equations for adults and Schwartz and Counahan-Barratt equations for children. Cystatin C measurement has been recommended as a screening test of renal dysfunction in children with liver disease and liver transplantation. Measurement of cystatin $\mathrm{C}$ can also be used for follow-up of renal function of pediatric solid organ transplants.

Controversy prevails regarding the use of cystatin $\mathrm{C}$ as a marker of GFR during pregnancy. But most studies have recommended cystatin $\mathrm{C}$.

Whether the measurement of cystatin $\mathrm{C}$ may help to reflect the real situation of renal function more precisely in cancer patients is a matter of debate. So, the value of cystatin $C$ as a useful marker of GFR in clinical oncology has to be studied in more detail. 


\section{Conclusions}

Results of our review study suggest that cystatin $\mathrm{C}$ is a better marker of renal function compared to serum creatinine and other endogenous markers irrespective of age, sex and clinical condition. Value of cystatin $\mathrm{C}$ as a marker of renal function in pregnancy is yet to be proved convincingly. Moreover, further pharmacokinetic evaluation is needed to determine whether serum creatinine or serum cystatin $\mathrm{C}$ is the better marker for prediction of drug clearance and drug monitoring.

\section{References}

1. Turner AN, Savil J, Stewart LH, Cumming A. Kidney and genitourinary disease. In: Haslett C, Chilvers ER, Boon NA, Colledge NR \& Hunter JAA (eds). Davidson's principles and practice of medicine. 19th edn. Edinburgh: Churchill Livingstone, 2002: 575-639.

2. Herget-Rosenthhal S, Pietruck F, Volbracht L, Philipp T, Kribber A. Serum cystatin C-a superior marker of rapidly reduced glomerular filtration after uninephrectomy in kidney donors compared to creatinine. Clin Nephrol 2005; 64: 41-46.

3. Spencer K. Analytical reviews in clinical biochemistry: The estimation of creatinine. Ann. Clin. Biochem. 1986; 23: $1-25$.

4. Payne RB. Creatinine clearance: a redundant clinical investigation. Ann. Clin. Biochem.1986; 26: 243-250.

5. Weber JA, van Zanten AP. Interferences in current methods for measurements of creatinine. Clin Chem 1991; 37: 695-700. [PMID: 2032322]

6. Lettellier G, Desjarlais F. Analytical interference of drugs in clinical chemistry: II-The interference of three cephalosporins with the determination of serum creatinine concentration by the Jaffe reaction. Clin Biochem 1985; 18: 352-356. [PMID: 4092352]

7. Guyton AC, Hall JE. Urine formation by the kidneys: I. Glomerular filtration, renal blood flow, and their control. In: Textbook of medical physiology. 11th edn. New York: Elselvier, 2006: 307-326.

8. Newman DJ, Price CP. Renal function and nitrogen metabolism. In: Burtis CA, Ashwood ER (eds). Tietz textbook of clinical chemistry. 3rd edn. Philadelphia: Harcourt Brace \& Company and W.B. Saunders Company, 1999: 1204-1270.

9. Levin A. Cystatin C, serum creatinine, and estimates of kidney function: searching for better measures of kidney function and cardiovascular risk. Ann Intern Med 2005; 144(7): 586-588.
10. Ayatse JOJ, Kwan JTC. Relative sensitivity of serum and urinary retinol binding protein and $\alpha_{1}$-microglobulin in the assessment of renal function. Ann. Clin. Biochem. 1991; 28: 514-516.

11. Grubb A. Diagnostic value of analysis of cystatin $\mathrm{C}$ and protein HC in biological fluids. Clin. Nephrol. 1992; 38 (Suppl 1): 520-527.

12. Newman DJ, Thakkan H, Edwards RG, Wilkie M, White T, Grubb AO et al. Serum cystatin C measured by automated immunoassay: a more sensitive marker of changes in GFR than serum creatinine. Kidney Int 1995; 47: 312-318.

13. Kyhse-Anderson J, Schmidt C, Nordin G, Andersson B, Nilsson-Ehle P, Lindström V et al. Serum cystatin C, determined by a rapid, automated particle enhanced turbidimetric method, is a better marker than serum creatinine for glomerular filtration rate. Clin Chem 1994; 40: 1921-1926.

14. Finney H, Newman DJ, Gruber W, Merle P, Price CP. Initial evaluation of cystatin $\mathrm{C}$ measurement by particle enhanced immunonephelometry on the Behring nephelometer systems (BNA, BNII). Clin Chem 1997; 43(6): 1016-1022.

15. Laterza OF, Price CP, Scott MG. Cystatin C: an improved estimation of glomerular filtration rate. Clin Chem 2000; 48(5): 699-707.

16. Levy AS, Berg RL, Glassman JJ, Hall PM, Walker WG. Creatinine filtration, secretion and excretion during progressive renal disease. Kidney Int 1989; 36 (Suppl 27): 73-80.

17. Adeera L. Cystatin C, serum creatinine, and estimates of kidney function: searching for better measures of kidney function and cardiovascular risk. Ann Intern Med 2005; 142(7): 586-588.

18. Stevens LA, Levy AS. Chronic kidney disease in the elderly - how to assess risk. N Engl J Med 2005; 352(20): 2122-2124.

19. Sjostrom P, Tidman M, Jones I. Determination of the production rate and non-renal clearance of cystatin $\mathrm{C}$ and estimation of the glomerular filtration rate from the serum concentration of cystatin C in humans. Scand J Clin Lab Invest 2005; 65(2): 111-124.

20. Hojs R, Bevc S, Antolinc B, Gorenjak M, Puklavec L. Serum cystatin $C$ as an endogenous marker of renal function in the elderly. Int J Clin Pharmacol 2004; 24(2-3): 49-54.

21. Hertlova M, Surel S, Senkyrik M, Kralova E, Novotna $\mathrm{H}$. Cystatin $\mathrm{C}$ in estimates of glomerular filtration in patients with renal disease - initial experience. Vnitr Lek 2001; 47(1): 10-16. 
22. Uzun H, Ozmen Keles M, Ataman R, Aydin S, Kalender B, Uslu E et al. Serum cystatin C level as a potentially good marker for impaired kidney function. Clin Biochem 2005; 38(9): 792-798.

23. Villa P, Jimenez M, Soriano MC, Manzanares J, Casasnovas P. Serum cystatin C concentration as a marker of acute renal dysfunction in critically ill patients. Crit Care 2005; 9(2): 139-143.

24. Wulkan R, den Hollander J, Berghout A. Cystatin C: unsuited to use as a marker of kidney function in the intensive care unit. Crit Care 2005; 9(5): 531-532.

25. Hoek FJ, Kemperman FAW, Krediet RT. A comparison between cystatin $\mathrm{C}$, plasma creatinine and the Cockroft and Gault formula for the estimation of glomerular filtration rate. Nephrol Dial Transplant 2003; 18: 20242031.

26. Keevil BG, Kilpatrick ES, Nichols SP, Maylor PW. Biological variation of cystatin $\mathrm{C}$ : implications for the assessment of glomerular filtration rate. Clin Chem 1998; 44(7): 1535-1539.

27. Rule AD, Bergstralh EJ, Slezak JM, Bergert J, Larson TS. Glomerular filtration rate estimated by cystatin C among different clinical presentations. Kidney Int 2006; 69(2): 399-405.

28. Grubb A, Nyman U, Bjork J, Lindstrom V, Rippe B, Sterner $\mathrm{G}$ et al. Simple cystatin C-based prediction equations for glomerular filtration rate compared with the modification of diet in renal disease prediction equation for adults and the Schwartz and the CounahamBarratt prediction equations for children. Clin Chem 2005; 51(8): 1420-1431.

29. Perkins BA, Nelson RG, Ostrander BE, Blouch KL, Krolewski AS, Myers BD et al. Detection of renal function decline in patients with diabetes and normal or elevated GFR by serial measurements of serum cystatin C concentration: results of a 4-year follow-up study. J Am Soc Nephrol 2005; 16(5): 1404-1412.

30. Ascic-Buturovic B, Cavaljuga S. Cystatin C as a marker for detection of early renal failure in diabetes type 2 patients. Bosn J Basic Med Sci 2005; 5(4): 68-72.

31. Oddoze C, Morange S, Portugal H, Berland Y, Dussol B. Cystatin $\mathrm{C}$ is not more sensitive than creatinine for detecting early renal impairment in patients with diabetes. Am J Kidney Dis 2001; 38(2): 310-316.

32. Uslu S, Efe B, Alatas O, Kebapci N, Colak O, Demirustu $C$ et al. Serum cystatin $C$ and urinary enzymes as screening markers of renal dysfunction in diabetic patients. J Nephrol 2005; 18(5): 559-567.

33. Mendiluce A, Bustamante J, Martin D, Santos M, Bustamante R, Pascual P et al. Cystatin C as a marker of renal function in kidney transplant patients. Transplant Proc 2005; 37(9): 3844-3847.

34. Samyn M, Cheeseman P, Bevis L, Taylor R, Samaroo B, Buxton-Thomas $\mathrm{M}$ et al. Cystatin $\mathrm{C}$, an easy and reliable marker for assessment of renal dysfunction in children with liver disease and after liver transplantation. Liver Transpl 2005; 11(3): 264-266.

35. Poge U, Gerhardt T, Stoffel-Wagner B, Klehr HU, Sauerbruch T, Woitas RP. Calculation of glomerular filtration rate based on cystatin $\mathrm{C}$ in cirrhotic patients. Nephrol Dial Transplant 2006; 21(3): 660-664.

36. Akbari A, Lepage N, Keely E, Clark HD, Jaffey J, MacKinnon $\mathrm{M}$ et al. Cystatin-C and beta trace protein as markers of renal function in pregnancy. BJOG 2005; 112(5): 575-578.

37. Strevens H, Wide-Swensson D, Torffvit O, Grubb A. Serum cystatin $\mathrm{C}$ for assessment of glomerular filtration rate in pregnant and nonpregnant women. Indications of altered filtration process in pregnancy. Scand J Clin Lab Invest 2002; 62: 141-147.

38. Strevens H, Wide-Swensson D, Grubb A. Serum cystatin $\mathrm{C}$ is a better marker for preeclampsia than serum creatinine or serum urate. Scand J Clin Lab Invest 2001; 61: 575-580.

39. Strevens H, Wide-Swensson D, Grubb A, Hansen A, Horn $\mathrm{T}$, Ingemarsson $\mathrm{I}$ et al. Serum cystatin $\mathrm{C}$ reflects glomerular endotheliosis in normal, hypertensive and preeclamptic pregnancies. Br J Obstet Gynecol 2003; 110: 825-830.

40. Moodley J, Gangaram R, Khanyile R, Ojwang PJ. Serum cystatin $\mathrm{C}$ for assessment of glomerular filtration rate in hypertensive disorders of pregnancy. Hypertens Pregnancy 2004; 23(3): 309-317.

41. Filler G, Foster J, Acker A, Lepage N, Akbari A, Ehrich JH. The Cockroft-Gault formula should not be used in children. Kidney Int 2005; 67(6): 2321-2324.

42. Corrao AM, Lisi G, Di Pasqua G, Guizzardi M, Marino $\mathrm{N}$, Ballone $\mathrm{E}$ et al. Serum cystatin $\mathrm{C}$ as a reliable marker of changes in glomerular filtration rate in children with urinary tract malformations. J Urol 2006; 175(1): 303-309.

43. Podracka L, Feber J, Lepage N, Filler G. Intra-individual variation of cystatin $\mathrm{C}$ and creatinine in pediatric solid organ transplant recipients. Pediatr Transplant 2005; 9(1): 28-32.

44. Ozer BA, Baykal A, Dursan B, Gultekin M, Suleymanlar G. Can cystatin $\mathrm{C}$ be a better marker for the early detection of renal damage in primary hypertensive patients? Ren Fail 2005; 27(3): 247-253.

45. Artunc FH, Fischer IU, Risler T, Erley CM. Improved 
estimation of GFR by serum cystatin C in patients undergoing cardiac catheterization. Int J Cardiol 2005; 102(2): 173-178.

46. Abu-Omar Y, Mussa S, Naik MJ, MacCarthy N, Standing $\mathrm{S}$, Taggrat DP. Evaluation of cystatin $\mathrm{C}$ as a marker of renal injury following on-pump and off-pump coronary surgery. Eur J Cardiothoracic Surg 2005; 27(5): 893-898.

47. Manetti L, Pardini E, Genovesi M, Campomori A, Grasso L, Morselli LL et al. Thyroid function differently affects serum cystatin $\mathrm{C}$ and creatinine concentrations. J Endocrinol Invest 2005; 28(4): 346-349.

48. Pont'uch P, Lehotska A, Parrak V, Martakova L, Fekete J. Serum cystatin $\mathrm{C}$ in haemodialysed patients. Vnitr Lek 2001; 47(1): 4-9.

49. Holweger K, Bokemeyer C, Lipp HP. Accurate measurement of individual glomerular filtration rate in cancer patients: an ongoing challenge. J Cancer Res Clin Oncol 2005; 131(9): 559-567.

50. Kos J, Stabuc B, Cimerman N, Brunner N. Serum cystatin $\mathrm{C}$, a new marker of glomerular filtration rate, is increased during malignant progression. Clin Chem 1998; 44: 2556-2557.

51. Demirtas S, Akan O, Can M, Elmali E, Akan H. Cystatin $\mathrm{C}$ can be affected by nonrenal factors: a preliminary study on leukemia. Clin Biochem 2006; 39: 115-118.

52. Thomas F, Seronie-Vivien S, Gladieff L, Dalenc F, Durrand $\mathrm{V}$, Malard L et al. Cystatin $\mathrm{C}$ as a new covariate to predict renal elimination of drugs: application to carboplatin. Clin Pharmacokinet 2005; 44(12): 1305-1316.

53. Hoppe A, Seronie-Vivien S, Thomas F, Delord JP, Malard $\mathrm{L}$, Canal $\mathrm{P}$ et al. Serum cystatin $\mathrm{C}$ is a better marker of topotecan clearance than serum creatinine. Clin Cancer Res 2005; 11(8): 3038-3044.

54. Fried LF, Katz R, Sarnak MJ, Shlipak MG, Chaves PH Jenny NS et al. Kidney function as a predictor of noncardiovascular mortality. J Am Soc Nephrol 2005; 16(12): 3728-3735.

55. Ricci Z, Ronco C. Year in review: critical care 2004 - nephrology. Crit Care 2005; 9(5): 523-527.

56. Shlipak MG, Matsushita K, Arnlov J, Inker LA, Katz R, Polkinghorne $\mathrm{KR}$ et al. Cystatin $\mathrm{C}$ versus creatinine in determining risk based on kidney function. N Engl J Med 2013; 369(10): 932-943.

57. Inker LA, Schmid CH, Tighiouart H, Eckfeldt JH, Feldman HI, Greene T et al. Estimating glomerular filtration rate from serum creatinine and cystatin C. N Engl J Med 2012; 367(1): 20-29.

58. Teo BW, Xu H, Wang D, Li J, Sinha AK, Shuter B et al. Estimating glomerular filtration rates by use of both cystatin $\mathrm{C}$ and standardized serum creatinine avoids ethnicity coefficients in Asian patients with chronic kidney disease. Clini Chem 2012; 58(2): 450-457.

59. Barsoum RS. Chronic kidney disease in the developing world. N Eng J Med 2006; 354(10): 997-999. 